\title{
O USO DAS EXIGÊNCIAS TÉCNICAS AMBIENTAIS INTERNACIONAIS NO DESENVOLVIMENTO INOVATIVO DE DEFENSIVOS AGRÍCOLAS
}

\section{THE USE OF ENVIRONMENTAL INTERNATIONAL TECHNICAL REQUIREMENTS IN INNOVATIVE DEVELOPMENT OF NEW PESTICIDES.}

\author{
Ricardo Kropf Santos Fermam \\ rkfermam@inmetro.gov.br \\ Instituto Nacional de Metrologia, Qualidade e Tecnologia (INMETRO) \\ Adelaide Maria de Souza Antunes \\ adelaide@eq.ufrj.br \\ Instituto Nacional de Propriedade Industrial (INPI)
}

\begin{abstract}
RESUMO
Os requisitos técnicos ambientais são muitas vezes vistos como barreiras técnicas ao comércio dentro de um processo de negócio. Eles também são considerados como obstáculos à inovação por parte das empresas que precisam cumprir com eles. No entanto, seria possível utilizar estes requisitos para o desenvolvimento de novos e inovadores produtos? Este artigo tem como objetivo demonstrar como isso pode ser feito, a partir de uma classe de produtos que possuem rigorosos requisitos ambientais: produtos de proteção das culturas.
\end{abstract}

Palavras-chaves: Defensivos, inovação, meio ambiente, barreiras técnicas.

\section{ABSTRACT}

The environmental technical requirements are often perceived as technical barriers to trade within a business process. They are also considered as impediments to innovation by firms that need to comply with them. However, it would be possible to use these requirements in the development of innovative new products? This article aims to demonstrate how this can be done, from a class of products that have stringent environmental requirements: crop protection products.

Keywords: Pesticides, innovation, environment, technical barriers.

\section{INTRODUÇÃO}

As exigências técnicas são fundamentadas em questões relacionadas à saúde, à segurança e ao meio ambiente e especificam padrões mínimos que os produtos 
devem atender para que possam ser comercializados. Elas materializam-se sob a forma de normas técnicas (voluntárias), regulamentos técnicos (compulsórios), procedimentos de avaliação da conformidade ${ }^{1}$ e acordos ambientais multilaterais ${ }^{2}$, podendo conter disposições sobre metrologia, terminologia, símbolos, embalagem, marcação ou rotulagem aplicáveis ao produto, processo ou método de produção. Tassey (2005) define estas exigências como sendo "infra-tecnologias".

Estas exigências são, em geral, percebidas por um setor ou país de forma negativa, isto é, como repressora ao desenvolvimento do setor ou país em questão, pela criação de custos adicionais referentes à necessidade de adequações do produto ou do processo produtivo. Quando vinculadas a um processo de exportação, estas exigências são conhecidas como "barreiras técnicas ao comércio".

Apesar de haver várias formas de definir barreiras técnicas às exportações, de acordo com as regras estipuladas pela Organização Mundial do Comércio (OMC) é possível afirmar que: "Barreiras Técnicas ao Comércio são barreiras comerciais derivadas da utilização de normas ou regulamentos técnicos não transparentes ou que não se baseiem em normas internacionalmente aceitas ou, ainda, decorrentes da adoção de procedimentos de avaliação da conformidade não transparentes ou demasiadamente dispendiosos, bem como inspeções excessivamente rigorosas". (INMETRO, 2009)

Existe uma classe de barreiras técnicas que é especialmente difícil de superar. Tratam-se das barreiras técnicas que surgem a partir de exigências ambientais. Isso se deve porque via de regra é complicada a precisa identificação da real intenção do país importador na implementação de uma medida ambiental sobre certos produtos. Como explica Ansanelli (2009), "em muitos casos as medidas restritivas estabelecidas

\footnotetext{
${ }^{1}$ Demonstração de que os requisitos especificados relativos a um produto, processo, sistema, pessoa ou organismo são atendidos. (ABNT NBR ISO/IEC 17000:2005)

${ }^{2}$ Os Acordos Multilaterais são acordos firmados por três ou mais sujeitos de direito internacional no âmbito internacional, podendo versar sobre os mais diversos temas, como cooperação econômica ou segurança. Os acordos ambientais multilaterais ("multilateral environmental agreements" ou "MEA", na sigla em inglês) são acordos celebrados no nível internacional com o objetivo de promover a proteção do meio ambiente e o desenvolvimento sustentável.

3 "Estas infra-tecnologias - ou tecnologias estruturais - podem ser definidas como um conjunto variado de 'ferramentas técnicas' necessárias à condução eficiente de todas as fases de $\mathrm{P} \& \mathrm{D}$, para controlar os processos de produção e para executar transações de mercado para bens de base tecnológica complexa. Elas incluem medições e métodos de ensaio,
} 
pelo país importador sobre determinados produtos visam garantir objetivos legítimos de proteção ambiental, mas em outros, tais exigências podem ser medidas protecionistas revestidas de pretextos ambientais." Os países em desenvolvimento, em especial, enfrentam maiores dificuldades no cumprimento das exigências ambientais externas, pois são exportadores de produtos primários e possuem deficiências em termos de recursos técnicos, financeiros e institucionais.

Essas exigências técnicas são particularmente importantes com relação a uma classe de substâncias utilizadas para garantir a produtividade agrícola: os defensivos agrícolas (FERMAM e ANTUNES, 2008). Em se tratando do setor de defensivos agrícolas, merecem destaque as exigências técnicas ambientais, utilizados como barreiras técnicas ao comércio. Estas exigências são manifestas de forma prática em normas técnicas, em regulamentos técnicos e em acordos multilaterais ambientais, podendo envolver, em última análise, questões ligadas à metrologia química e avaliação da conformidade, tem sido historicamente percebidos pelas empresas dos países em desenvolvimento de forma negativa, como protecionismo de cunho técnicoambiental. (FERMAM e ANTUNES, 2009)

De fato, o crescente debate sobre as exigências técnicas para acesso a mercados, principalmente relacionado aos defensivos agrícolas, tem gerado entraves comerciais para o setor agrícola os quais, por sua vez, impactam no setor de defensivos. Contudo, é possível fazer uso dos requisitos ambientais no comércio internacional, relacionada aos defensivos agrícolas, de forma inovadora - como ferramenta de inovação na indústria. Esse é o objetivo do presente artigo, baseado na Tese de Doutorado defendida pelo autor.

O artigo possui mais seis seções. Na segunda, são apresentados alguns principais conceitos relacionados aos defensivos agrícolas. Na terceira, é apresentado o processo genérico de desenvolvimento de defensivos agrícolas. Na quarta, apresenta-se a metodologia empregada, na quinta seção os resultados obtidos e a respectiva discussão e, finalmente, na sexta seção as conclusões. 


\section{Os Defensivos Agrícolas.}

Há ampla literatura e várias terminologias sobre os defensivos agrícolas, o que exemplifica a multiplicidade de visões que cercam essas substâncias químicas utilizadas na agricultura. O Novo Aurélio Século XXI (FERREIRA, 1999) conceitua "defensivo agrícola" como o "produto químico utilizado no combate e prevenção de pragas agrícolas". Esta terminologia é adotada pelas indústrias produtoras desses compostos, pois o termo utilizado traz a ideia de proteção (defesa) dos produtos agrícolas da ação de pragas e doenças que poderiam causar prejuízos econômicos. Os defensivos agrícolas compreendem uma categoria especial de insumos. Promovem benefícios indiretos à produtividade, uma vez que o objetivo de sua utilização é o de evitar a perda nas safras, provocada pelo ataque prejudicial de pragas e doenças às culturas.

A literatura anglo-americana emprega o termo pesticides, pesticida em português, mas exprime a ideia equivocada de combater apenas pestes. O termo praguicida, também encontrado, é igualmente um termo muito limitado, não representando a realidade desses compostos que agem também em organismos que não são considerados pragas.

O termo mais popular, usado atualmente no meio agrícola e na sociedade como um todo, é agrotóxico. Este termo tem sentido amplo, incluindo todos produtos utilizados nos agroecossistemas para combater pragas e doenças. Essa terminologia não foge do sentido "tóxico de uso agrícola" (agro + tóxico), tendo a toxicologia como ciência que estuda seus efeitos. Esse termo é utilizado por vários autores de diferentes áreas no Brasil, bem como por autoridades públicas.

O termo agrotóxico surge no movimento ambientalista brasileiro, início da década de 80, com a pretensão de dar conotação forte e pejorativa a esses produtos, como forma de alertar a sociedade sobre sua prejudicialidade. Bem como, abrir a discussão sobre os "defensivos agrícolas", referência utilizada pelos fabricantes destes produtos. Segundo a lei brasileira no. 7.802 de 11 de julho de 1989, artigo 2ํㅡ, são considerados agrotóxicos e produtos afins: 
Produtos e os agentes de processos físicos, químicos ou biológicos, destinados ao uso nos setores de produção, no armazenamento e beneficiamento de produtos agrícolas, nas pastagens, na proteção de florestas, nativas ou implantadas, e de outros ecossistemas, e também de ambientes urbanos, hídricos e industriais, cuja finalidade seja alterar a composição da flora ou da fauna, a fim de preservá-las da ação danosa de seres vivos considerados nocivos, substâncias e produtos, empregados como desfolhantes, dessecantes, estimuladores e inibidores de crescimento.

De acordo com o Decreto 4074/2002, um defensivo agrícola (produto técnico ${ }^{4}$ ) é composto pelo ingrediente ativo (molécula com atividade química e/ou biológica, a qual confere eficácia ao mesmo) adicionado os ingredientes inertes ${ }^{5}$, $\operatorname{aditivos}^{6}$ e adjuvantes $^{7}$. (BRASIL, 2002)

Existem diversos critérios para classificação dos defensivos agrícolas. Alguns dos mais comuns são: (i) classificar de acordo com os tipos de alvos preferenciais sobre os quais atuam (inseticidas, herbicidas, fungicidas, rodenticidas, entre outros); (ii) classificar segundo a classe química a que pertencem (organoclorados, organofosforados, carbamatos, piretróides, triazinas, etc); (iii) classificar conforme a sua maior ou menor toxicidade aguda sobre os seres vivos. (FERMAM, 2009)

Os defensivos desempenham importante papel na agricultura. Conforme Oliveira e Silva e da Costa (2012), sem o uso dessas substâncias, as perdas em razão das pestes situar-se-iam entre $30 \%$ e $40 \%$ da cultura plantada, com seus maiores valores ocorrendo nos países em desenvolvimento. De fato, os sucessivos aumentos na produtividade agrícola brasileira não teriam sido alcançados sem a correta e segura utilização dos defensivos agrícolas (NINAUT e OLIVEIRA, 2010). Sem eles, a demanda por alimentos se tornaria rapidamente maior do que a oferta devido a perdas

\footnotetext{
${ }^{4}$ Produto obtido diretamente de matérias-primas por processo químico, físico ou biológico, destinado à obtenção de produtos formulados ou de pré-misturas e cuja composição contenha teor definido de ingrediente ativo e impurezas, podendo conter estabilizantes e produtos relacionados, tais como isômeros.

${ }^{5}$ Substância ou produto não ativo em relação à eficácia dos defensivos e afins, usado apenas como veículo, diluente ou para conferir características próprias às formulações.

${ }^{6}$ Substância ou produto adicionado a defensivos, componentes e afins, para melhorar sua ação, função, durabilidade, estabilidade e detecção ou para facilitar o processo de produção.

${ }^{7}$ Produto utilizado em mistura com produtos formulados para melhorar a sua aplicação.
} 
por pragas. Por isso, são produtos-chave para garantir a competitividade do setor agrícola num mundo globalizado. (FERMAM e ANTUNES, 2009)

Segundo a ABIFINA (2013), o segmento de defensivos agrícolas vem apresentando faturamento crescente nos últimos anos, alcançando US\$ 8,5 bilhão em 2011, com alta de 16\% em relação a 2010 (US\$ 7,3 bilhão). Os números colocam o Brasil na liderança no consumo mundial dessas substâncias. Apesar desses números, o setor registra um déficit comercial crescente, sendo de US\$1.110,6 milhões em 2010 e de US\$1.487,1 milhões em 2011, representando um crescimento de 33,9\% no período. Esse panorama é verificado porque as importações saltaram de US $\$ 1.533,9$ milhões em 2010 para cerca de US\$ 1.958,8 milhões em 2011, um aumento de $27,7 \%$, enquanto que o aumento observado no mesmo período para as exportações de defensivos foi de cerca de $11,4 \%$.

\section{Desenvolvimento de Novos Defensivos.}

A inovação na indústria de defensivos agrícolas, no que se refere ao desenvolvimento de novos produtos, opera num modelo interativo, determinado, dentre outros, pela capacidade de geração de novas moléculas químicas e pelo sistema regulatório público (MARTINELLI JR e WAQUIL, 2002).

Para os defensivos agrícolas, o binômio estrutura-atividade se corporifica na busca de uma molécula química que tenha uma ação biológica sobre uma determinada praga/erva. Dessa forma, cada empresa busca ter um conjunto próprio de produtos, suficientemente diferenciados quimicamente para serem patenteáveis, e que tenham efeitos biológicos desejáveis sobre pragas/ervas específicas. (FRENKEL e SILVEIRA, 1996)

O processo de desenvolvimento de novos defensivos agrícolas é lento e financeiramente custoso. Depois da descoberta, o processo de desenvolvimento acontece em várias etapas. Primeiro, os pesquisadores conduzem screenings (também conhecida como High Throughput Screening ou Seleção de Alto Rendimento) onde os limiares biológicos são determinados (FLETCHER, 2006). Depois, um grupo multidisciplinar determina que compostos merecem investigações posteriores. 
De forma geral, High Throughput Screening (HTS) é a integração de tecnologias (automação de laboratório, avaliação tecnológica, micro-instrumentação, estatística multivariável, etc) para selecionar com rapidez compostos químicos que possuam uma atividade desejada. Há, em princípio, três abordagens diferentes do HTS (SCHNECKE and BOSTRÖM, 2006):

a) Seleção Randômica (Random screening, ou full HTS): São realizados testes em todos os compostos, ou num grande subconjunto de compostos disponíveis, normalmente em diversas etapas, que se iniciam com uma avaliação primária de alto rendimento, seguida por uma ou mais etapas para obter alvos (por exemplo: controle de identidade e pureza nas amostras que apresentam baixa atividade micromolar numa determinada concentração-resposta selecionada).

b) Seleção Focalizada: É a seleção de um subconjunto de uma coleção de compostos que são escolhidos com base no conhecimento sobre os mesmos, possuindo atividade contra um alvo específico. Quando há gargalos na capacidade de ensaios ou no fornecimento de proteínas, a seleção focalizada é o único modo de identificar um grande número de pontos de partida. É, também, o método de escolha para recuperar séries de dados de um projeto anterior que tenha sido desenvolvido com a abordagem full HTS.

c) Seleção Sequencial: Realizada através de diversas iterações, inicia-se a partir de um subconjunto representativo da coleção completa de compostos. A cada iteração, os aglomerados (clusters) de compostos ativos são expandidos até que um número suficiente de séries é identificado.

A figura 1 ilustra o processo integrado de descoberta e otimização de defensivos. Posteriormente, a área de desenvolvimento de processos sintetiza a substância química (o ingrediente ativo) mais promissora em grandes quantidades. A partir da síntese desta substância, serão conduzidos testes de eficácia no laboratório e em campo, bem como examinados a toxicidade química, e estimados os custos de produção. Estes dados técnicos e o custo são então repassados aos gerentes da empresa que determinam se a companhia deve prosseguir em pequenos testes de campo. 


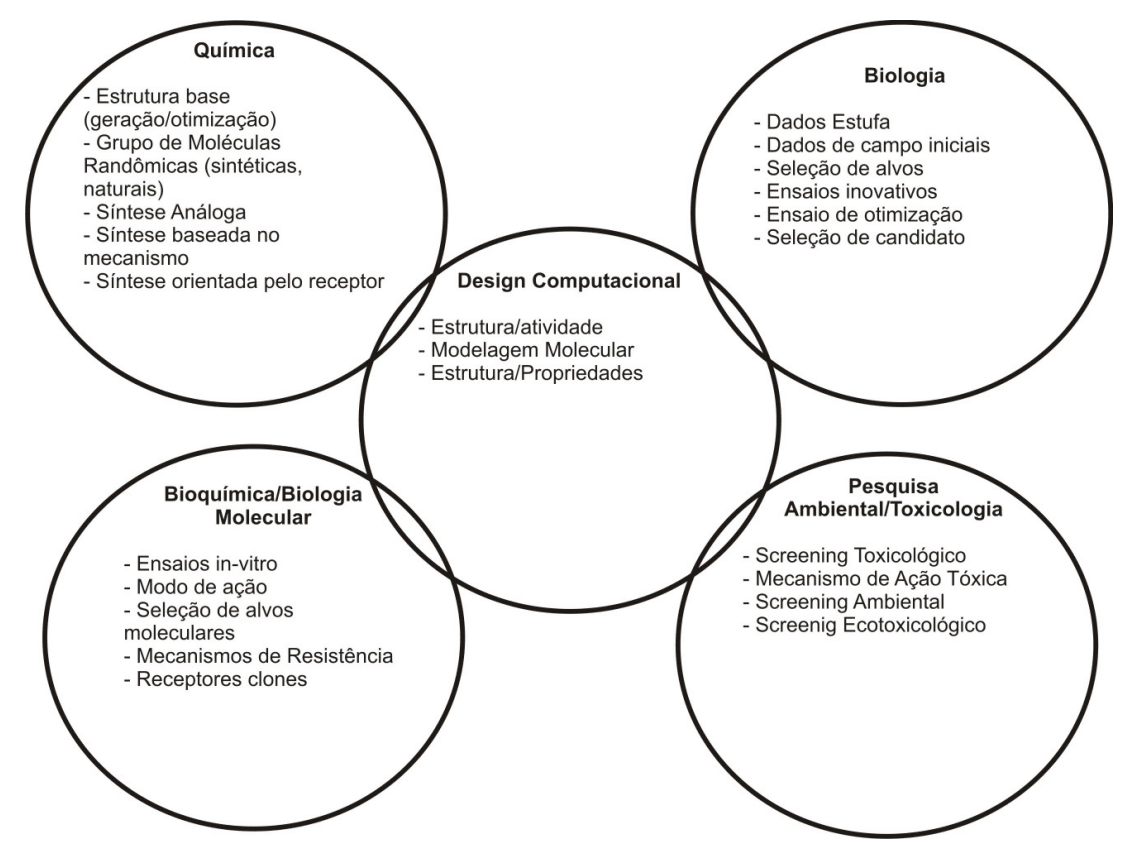

Figura 1: Processo Integrado de Descoberta e Otimização de Defensivos. Elaboração própria, conforme Stetter, 1998.

As substâncias químicas assim selecionadas devem ser submetidas a uma série de ensaios de campo ainda mais exigentes. Primeiro, pesquisadores usam testes de campo de pequena escala para determinar a eficácia do composto químico, comparando-o aos defensivos existentes. Eles também avaliam o impacto do solo, da luz solar (fotólise), dos micróbios e do clima sobre a efetividade da substância. Se a substância em questão tem comportamento semelhante à dos defensivos existentes, a firma obtém uma permissão de uso experimental (EUP), emitida pelo órgão ambiental ${ }^{8}$ (no caso dos EUA, o Environmental Protect Agency - EPA). (FERMAM, 2009)

Este EUP permite a companhia conduzir grandes testes de campo. O órgão ambiental confere a EUP somente se crê que a evidência, prevista pela companhia, mostra que nenhum efeito adverso ambiental irá ocorrer. Se o órgão ambiental não confere a permissão, então a companhia deve especificar um novo teste de campo

\footnotetext{
${ }^{8}$ No Brasil, esta permissão, denominada "Registro Especial Temporário" (RET) é concedida pelo Instituto Brasileiro do Meio Ambiente e dos Recursos Naturais Renováveis (IBAMA), pela Agência Nacional de Vigilância Sanitária (ANVISA) e pelo Ministério da Agricultura, Pecuária e Abastecimento (MAPA), em conjunto. (INC, 25/2005)
} 
que atenda às objeções do órgão ambiental ou abandonar o desenvolvimento do defensivo.

Em grandes testes de campo, biólogos e outros especialistas conduzem estudos de metabolismo, meio ambiente, resíduos e toxicológicos, a fim de determinar o impacto do composto sobre seres humanos, animais, peixes e vida selvagem. Simultaneamente, engenheiros químicos e outros técnicos ligados à produção desenvolvem técnicas de formulação e métodos de produção.

A habilidade em selecionar compostos químicos com alta eficácia e que também atenda aos requisitos do órgão ambiental é extremamente importante. $A$ seleção de um composto que não atenda a estes requisitos leva a custos em pesquisa e tempo perdidos. Já a seleção de compostos de baixa eficácia não serão absorvidos pelo mercado. (FERMAM, 2009)

Assim, desenvolver uma estratégia de otimização dos ensaios é importante porque se a firma conduzir muitos testes, além do necessário, incorrerá em altos custos de desenvolvimento. Alternativamente, se a companhia conduzir poucos ensaios, aquém do necessário, ou se a qualidade dos dados obtidos é insatisfatória, haverá necessidade de novos ensaios adicionais ou de revisões nos dados, ocasionando atrasos na comercialização do produto e resultando em perdas de receita.

O aumento nos gastos em pesquisa, gerados por regulamentos técnicos, e o aumento do ciclo de desenvolvimento dos defensivos produzem altos custos e podem impedir que as firmas desenvolvam certos tipos de defensivos químicos. Altos custos ligados ao desenvolvimento e à regulamentação desencorajam alguns tipos de inovação, porque um produto deve proporcionar grandes receitas de forma a ser lucrativo. Conforme Ridley et al (1998), é cada vez mais difícil descobrir e lançar no mercado novos defensivos, justamente devido ao aumento das pressões de regulamentos ambientais e à natureza altamente competitiva desse mercado.

O aumento no tempo de desenvolvimento do defensivo é custoso para a companhia, porque leva a longos períodos de retorno dos investimentos. Adicionalmente, as companhias ganham proteção patentária durante o processo de 
desenvolvimento; logo, um longo período de desenvolvimento proporciona à companhia menos tempo para vender o defensivo como proprietária do produto. Por isso, num esforço para maximizar as chances de descobrir novos compostos ativos, a ênfase nos últimos anos tem sido o aumento no número de compostos testados. (RIDLEY et al, 1998)

Conforme estudo elaborado por Oliveira e Silva e da Costa (2012), para a obtenção de um novo princípio ativo, no início dos anos 1950 era necessário testar cerca de 1.300 moléculas; no início dos anos 1990, 45 mil moléculas; e, em 2000, cerca de 140 mil moléculas, ao custo de US\$ 184 milhões, valor elevado para US\$ 256 milhões em 2008. O aumento da quantidade de moléculas para o desenvolvimento de uma única molécula com capacidade de ser utilizada é algo custoso para a companhia, como pode ser visto. Obviamente, esse aumento nas moléculas a serem utilizadas no desenvolvimento reflete-se em longos períodos de retorno dos investimentos. Segundo a ANDEF (2010), o desenvolvimento de uma única molécula de defensivo pode levar de 10 a 12 anos.

Adicionalmente, para se ter uma idéia do processo de desenvolvimento de novos defensivos, a Bayer testa, em média, 10.000 defensivos potenciais por ano. Quando um ingrediente ativo mostra potencial herbicida, por exemplo, a cultura e o espectro da erva daninha serão ampliados. Dos 10.000 potenciais ingredientes ativos testados, somente 150 serão testados em doses comerciais; destes, somente 20 serão testados em campo. Ao final, apenas um ou dois produtos serão lançados no mercado. (BES, 2007)

Ressalte-se que há poucas variações no processo de desenvolvimento de defensivos quanto às classes (herbicidas, inseticidas e fungicidas) descrito acima; estas poucas variações referem-se à praga que se deseja combater (ervas daninhas, insetos e fungos, respectivamente) bem como o alvo onde o defensivo é testado. Como exemplo, o processo de desenvolvimento de herbicidas, utilizado pela Bayer, pode ser visto na figura 2 . 


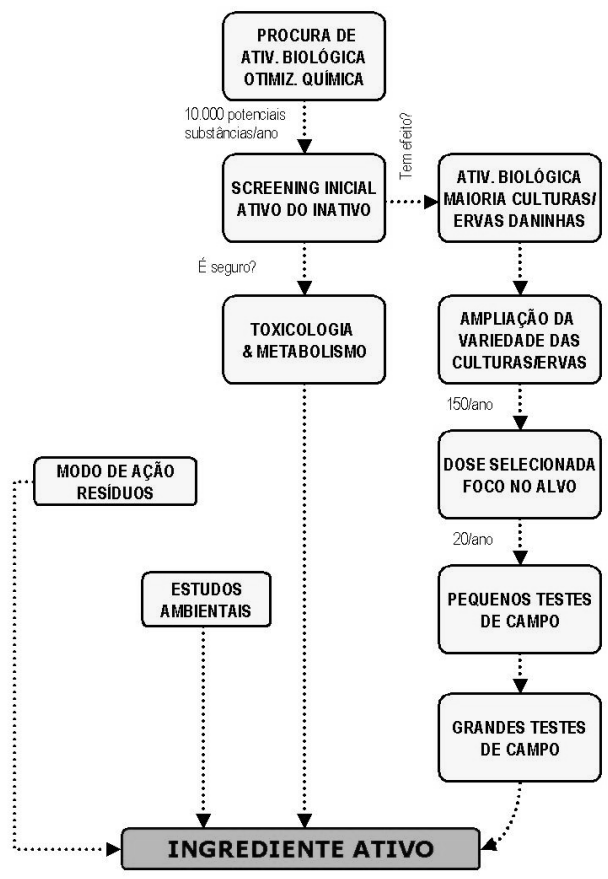

Figura 2: Processo de desenvolvimento de herbicidas da Bayer. (BES, 2007)

Conforme Silveira e Futino (1990) há, ainda, uma interação dinâmica entre pesquisa e ambiente que merece ser destacada: o próprio uso continuado de defensivos gera motivações para o lançamento de novos produtos. O uso prolongado dessas substâncias acaba gerando resistência às mesmas, reduzindo sua vida útil, se constituindo desse modo numa fonte de incentivo à geração de inovações.

\section{METODOLOGIA}

A metodologia empregada nesse artigo consiste na pesquisa em meio eletrônico das exigências ambientais contidas nos acordos ambientais internacionais específicos que tratam do tema "defensivos agrícolas". Uma vez tendo sido identificadas as exigências ambientais (técnicas) específicas para o setor de defensivos agrícolas estas exigências são então classificadas de forma sistemática, em termos das disposições neles contidas. Com essa etapa, pretende-se agrupar as disposições segundo uma provável afinidade entre elas, como por exemplo disposições quanto a estrutura química. Essa classificação possibilita um aspecto de 
previsibilidade, isto é, a partir da mesma torna-se possível identificar as tendências internacionais, referentes a futuras prescrições das disposições referentes àquele produto/setor.

Conforme Fermam e Antunes (2008), destacam-se pelo menos dois destes Acordos. O primeiro é a "The Rotterdam Convention on the Prior Informed Consent (PIC) Procedure for Certain Hazardous Chemicals and Pesticides in International Trade". O segundo acordo aplicável é a "Convention on the Control of Persistent Organic Pollutants 10" (também conhecida como "Stockholm Convention", em inglês, ou Convenção de Estocolmo ou ainda Convenção POP, em português). A Convenção visa limitar a poluição por poluentes orgânicos persistentes (POP). Define as substâncias abrangidas, mantendo contudo a possibilidade de acrescentar novas substâncias, e as regras relativas à sua produção, importação e exportação.

A Convenção de Roterdã (ou Convenção PIC) decorreu do Código Internacional de Conduta da FAO sobre a distribuição e uso de pesticidas, de 1985 e das Diretrizes de Londres, estabelecidas pelo PNUMA, em 1987, para o intercâmbio de informações no comércio internacional de substâncias químicas. A Convenção PIC é operacionalizada pela Conferência das Partes - COP; Comitê de Revisão Química ${ }^{11}$ CRC; e Secretariado.

Esta Convenção disponibiliza aos países importadores os instrumentos e as informações necessárias para identificar os perigos potenciais e excluir as substâncias químicas que eles não podem gerir com segurança (substâncias químicas proibidas ${ }^{12}$ ou severamente restritas e formulações de agrotóxicos severamente perigosas, conforme Art. 3ํㅜ , item 1).

\footnotetext{
${ }^{9}$ Disponível em http://www.pic.int/.

${ }^{10}$ Disponível em http://chm.pops.int.

${ }^{11}$ O Comitê de Revisão Química - CRC tem como principal função - a partir do exame das informações recebidas por meio de notificação de legislação proibitiva ou que restringe severamente o uso de determinada substância, recomendar a inclusão, ou não, da substância no Anexo III da Convenção. Cabe também ao CRC recomendar a exclusão de substâncias do Anexo III. O CRC elabora o Documento Orientador de Decisão (DGD), que é submetido à COP e disponibilizado às Partes, a fim de subsidiar suas respostas relativas ao consentimento sobre futuras importações das substâncias recém inseridas no Anexo III.

${ }^{12} \mathrm{O}$ termo "substância química proibida" se refere à uma substância química que tenha tido todos seus usos dentro de uma ou mais categoria proibidos por ação regulamentadora final, com vistas a proteger a saúde humana ou o meio ambiente. Inclui substâncias químicas inicialmente não aprovadas para uso, ou que tenham sido retiradas do mercado interno pela
} 
Conforme o Ministério do Meio Ambiente (2013), a Convenção de Estocolmo trata do gerenciamento, visando a eliminação, de substâncias químicas orgânicas que, segundo critérios definidos na própria convenção, são classificadas como sendo persistentes (não degradadas), passíveis de transporte a longa distância, pelo ar, água e solo, toxicologicamente preocupantes para a saúde humana e o meio ambiente.

Os poluentes orgânicos persistentes são substâncias químicas que, possuindo certas propriedades tóxicas, resistem, contrariamente a outros poluentes, à degradação, o que as torna particularmente nocivas para a saúde humana e o ambiente. Os POPs acumulam-se nos organismos vivos e propagam-se pelo ar, pela água e pelas espécies migratórias e acumulam-se nos ecossistemas terrestres e aquáticos (FERMAM, 2009). Moléculas de alto peso molecular, contendo halogênios e/ ou anéis aromáticos condensados são mais persistentes ${ }^{13}$. (FLORES et al, 2004)

A Convenção elegeu inicialmente doze destas substâncias químicas perigosas para serem banidas (conhecidas como "dirty dozens", ou "doze sujos"), são elas: as dioxinas, furanos, policloretos de bisfenilas (PCBs); DDT, clordano, heptacloro, hexaclorobenzeno (HCB), toxafeno, aldrin, dieldrin, endrin e mirex. A Convenção POP permite aos países signatários apresentarem mais substâncias químicas que tiverem as características de poluentes orgânicos persistentes como candidatos à lista de banimento.

\section{RESULTADOS}

No âmbito da Convenção PIC há, em seu Anexo III, um conjunto de várias substâncias que são sujeitas ao procedimento de consentimento prévio, num total de

\footnotetext{
indústria, ou que passaram a ser desconsideradas em processos nacionais de aprovação com provas irrefutáveis de que tais ações foram adotadas para proteger a saúde humana ou o meio ambiente;

${ }^{13}$ A persistência da substância no solo depende também da eficiência de processos físicos de transformação, como evaporação, lixiviação, erosão e absorção pelas raízes das culturas, como explica Flores et al (2004). Fatores ambientais como temperatura, conteúdo de matéria orgânica, acidez, umidade e tipo de solo influenciam, também, as taxas de degradação. Reações químicas, como hidrólise, podem ser pré-requisitos para o ataque microbiano. Percebe-se, então, que pode haver interação dos agentes físicos, químicos e biológicos na degradação dos defensivos no solo.
} 
43, dentre estas 32 são defensivos (incluindo 4 formulações severamente perigosas de defensivos) e 11 produtos químicos industriais.

Os defensivos ${ }^{14}$ são: 2,4,5-T (e seus sais), Alaclor, Aldicarb, Aldrin, Binapacril, Captafol, Clordano (BHC), Clordimeforme, Clorobenzilato, DDT, Dieldrin, Dinitro-ortocresol (DNOC) e seus sais, Dinoseb e seus sais e ésteres, 1,2-dibromoetano (EDB), Endosulfan, Dicloreto de Etileno, Óxido de Etileno, Fluoracetamida, $\mathrm{HCH}$ (mistura de isômeros), Heptacloro, Hexaclorobenzeno, Lindano, Compostos de mercúrio (inclusive compostos de mercúrio inorgânico, compostos aquilmercúricos e compostos arilmercúricos e alquiloxialquílicos), Monocrotofós, Paration, Pentaclorofenol (incluindo seus sais e ésteres) e tributil estanho.

Figuram também as seguintes formulações de defensivos, classificadas como severamente perigosas:

a) Benomil (concentração igual ou superior a 7\%), Carbofuram (concentração igual ou superior a 10\%) e Thiram (concentração igual ou superior a 15\%).

b) Metamidofós (formulações líquidas solúveis das substâncias que excedem $600 \mathrm{~g}$ de ingrediente ativo/1);

c) Fosfamidon (formulações líquidas solúveis das substâncias que excedem $1000 \mathrm{~g}$ de ingrediente ativo/1);

d) Paration Metílico (concentrados emulsificáveis com 19,5\%, 40\%, 50\%, 60\% de ingrediente ativo e pós contendo 1,5\%, 2\% e 3\% de ingrediente ativo);

Por sua vez, no âmbito da Convenção POP, além das 12 substâncias banidas inicialmente, constam nove (09) outras substâncias. Dentre estas, são defensivos as seguintes: clordecona, alfa hexaclorociclohexano, beta hexaclorociclohexano, lindano, pentaclorobenzeno. Consta também como POP em fase de banimento a mistura técnica de endosulfan (composta por seus isômeros alfa e beta), substância ainda em

\footnotetext{
${ }^{14}$ Todas essas substâncias possuem um número de registro internacional que as identifica. Esse número, conhecido como CAS (Chemical Abstract Service), é listado para cada uma das substâncias abrangidas na Convenção PIC. A partir do número de registro CAS, é possível obter informações acerca dos nomes sinônimos de cada uma dessas substâncias, bem como a fórmula molecular e a estrutural no site http://www.commonchemistry.org/.
} 
uso em muitos países ${ }^{15}$, apesar de suas características deletérias a saúde e ao meio ambiente.

\section{DISCUSSÕES}

Conforme o estudo realizado, as exigências técnicas ambientais envolvendo os defensivos agrícolas podem ser classificadas com relação a estrutura química. A classificação química dos defensivos listados no âmbito das Convenções PIC e POP podem ser vistas no quadro 1.

Quadro 1: Classificação Química dos Defensivos no âmbito das Convenções PIC e POP.

\begin{tabular}{|l|c|c|}
\hline SUBSTÂNCIA & CONVENÇÃO & $\begin{array}{l}\text { CLASSIFICAÇÃO } \\
\text { QUímICA }\end{array}$ \\
\hline $\begin{array}{l}\text { Alaclor, Captafol, } \\
\text { Clordimeforme, } \\
\text { Clorobenzilato, Dicloreto } \\
\text { de Etileno, Pentaclorofenol }\end{array}$ & PIC & \\
\hline $\begin{array}{l}\text { Endosulfan, HCH, } \\
\text { Lindano, DDT, Clordano, } \\
\text { Heptacloro, } \\
\text { Hexaclorobenzeno, Aldrin, } \\
\text { Dieldrin }\end{array}$ & PIC e POP & Organoclorado \\
\hline $\begin{array}{l}\text { Clordecona, } \\
\text { Pentaclorobenzeno, } \\
\text { Endrin, Mirex }\end{array}$ & POP & \\
\hline Fluoracetamida & PIC & Organofluorado \\
\hline
\end{tabular}

\footnotetext{
${ }^{15} \mathrm{O}$ endosulfan é um inseticida que tem sido usado desde os anos 1950 para controlar pragas, moscas tsé-tsé e ectoparasitas de bovinos e como conservante de madeira. Como um inseticida de amplo espectro, endosulfan é atualmente utilizado para controlar uma vasta gama de pragas de uma variedade de culturas, incluindo o café, algodão, arroz, sorgo e soja.
} 


\begin{tabular}{|l|c|l|}
\hline Aldicarb & PIC & Carbamato \\
\hline $\begin{array}{l}\text { Binapacril, Dinitro-orto- } \\
\text { cresol (DNOC), Dinoseb }\end{array}$ & PIC & Derivado do Fenol \\
\hline 1,2-dibromoetano (EDB) & PIC & Organobromado \\
\hline Óxido de Etileno & PIC & Óxido Orgânico \\
\hline Compostos de mercúrio & PIC & Organomercúrico \\
\hline Monocrotofós, Paration & PIC & Organofosforado \\
\hline Tributil estanho & PIC & Organoestânico \\
\hline
\end{tabular}

Como pode ser visto, das 30 substâncias listadas no quadro 1, 19 substâncias são organoclorados (com cloro em sua estrutura), 01 organofluorada (com flúor em sua estrutura), 01 organobromada (com bromo em sua estrutura). Cloro, Flúor e Bromo são elementos pertencentes a mesma família ou grupo químico, conhecida como halogênios; estes estão ligados a moléculas orgânicas nestas estruturas. Um exemplo pode ser visto na figura 3.

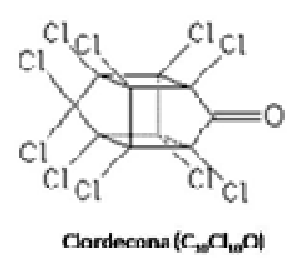

$\mathrm{Cl}$<smiles>ClC1C(Cl)C(Cl)C(Cl)C(Cl)C1Cl</smiles>

Hesaclorocidohsano [HCH] $\left[\mathrm{CH}_{2} \mathrm{O}_{4}\right]$
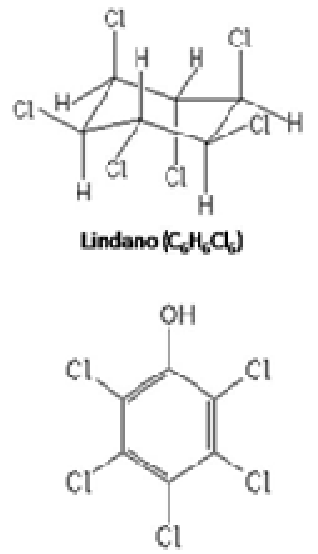

Pentadorcfenol $\left(C_{4} \mathrm{HCO}_{\mathrm{O}}\right.$ )

Figura 3: Exemplos de organoclorados. 
Com relação aos organoclorados, esta classe de defensivos ou está banida pelos países em sua totalidade ou quase totalidade. Observando as demais substâncias, é possível detectar também uma tendência com relação ao banimento de outros halogenetos ${ }^{16}$ de alquila (ou, em sua grande maioria, halogenetos de arila ${ }^{17}$ ), bem como de alguns organofosforados. Segundo a AENDA, "a família dos pesticidas organofosforados já é carta a ser descartada pelas grandes empresas que dominam o mercado" (AENDA, 2005). Há uma crescente aceitação, pelos países, de ingredientes ativos naturais ou que se assemelhem às substâncias naturais, de características mais favoráveis para o meio ambiente.

Segundo informações constantes no site da Convenção de Estocolmo, com relação ao endosulfan, um total entre 18.000 e 20.000 toneladas de endosulfan são produzidos anualmente no Brasil, China, Índia, Israel e Coréia, tendo sido descontinuada a sua produção na Colômbia, EUA e diversos países da Europa. Os maiores usuários de endosulfan (Argentina, Austrália, Brasil, China, Índia, México, Paquistão e Estados Unidos) utilizam um total de cerca de 15.000 toneladas de endosulfan por ano. O uso de endosulfan é proibido ou será eliminado em 60 países que, juntos, respondem por $45 \%$ do uso global atual. Algumas alternativas químicas e não-químicas estão sendo aplicadas em países onde endosulfan foi proibido ou está sendo progressivamente eliminados. No entanto, a Convenção reconhece que em alguns países pode ser difícil e/ou dispendioso substituir o endosulfan para culturas específicas e pragas complexas.

A análise realizada traz indicativos, para as empresas de defensivos agrícolas, acerca de que tipo de defensivo deverá ser objeto de investimentos em pesquisa e desenvolvimento (P\&D). O risco de investimentos para produção de substâncias organocloradas (ou organofosforadas) é muito mais alto, por exemplo, do que alguns tipos de carbamatos, dado o cenário internacional para o setor (mapeado a partir das exigências técnicas). Além disso, há culturas-chave em cada país, com toda uma

\footnotetext{
${ }^{16}$ Os haletos ou halogenetos (derivam do nome grego halos - sal) são compostos químicos que contém átomos dos elementos do grupo VII halogênios (flúor $(\mathrm{F})$, cloro $(\mathrm{Cl})$, bromo $(\mathrm{Br})$, iodo $(\mathrm{I})$ e astato $(\mathrm{At})$ ) em estado de oxidação -1. Suas características químicas e físicas lhe fazem ser parecidos do cloreto até o iodeto, sendo uma exceção o fluoreto.

${ }^{17}$ São compostos derivados formalmente dos hidrocarbonetos pela substituição de um ou mais átomos de H por átomos de halogênios..
} 
diversidade de pragas, que podem ser usadas pelas empresas, especialmente as micro, pequenas e médias, para focarem sua produção de defensivos, ampliando assim seu acesso a mercados.

Como abordado previamente, para o desenvolvimento de um novo defensivo, parte-se inicialmente de um conjunto de $10^{5}$ (ou 106 ) potenciais ingredientes ativos, para, ao final, obterem-se apenas 20 moléculas que detém condições de testes em campo. Altos custos e tempo com em testes químicos, biológicos e ambientais destas várias moléculas são empecilhos a ganhos de competitividade pela empresa.

Mas, e se a quantidade de moléculas envolvidas na partida inicial do desenvolvimento, candidatas a serem utilizadas como ingredientes ativos, fosse menor? Raciocinando-se em termos de tempo e custos, os ganhos gerados pela redução destes fatores acarretaria inevitavelmente em ganhos de competitividade para a empresa, especialmente para as micro, pequenas e médias. Para tal, as informações obtidas a partir da análise das exigências se constituem em útil ferramenta.

Para ilustrar a utilização dos requisitos como ferramenta norteadora de P\&D visando a redução de tempo e custos para as empresas e, consequentemente, ganhos de competitividade e de acesso a mercados, faz-se uso do seguinte exemplo hipotético: considere que, após a síntese combinatória de moléculas candidatas ao uso como ingrediente ativo de um dado defensivo, foi obtida a seguinte estrutura Markush $^{18}$, representada na figura 4.

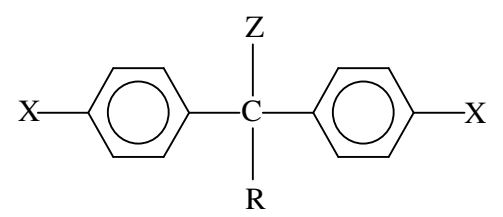

$\mathrm{X}:\left[\mathrm{Cl}, \mathrm{F}, \mathrm{C}_{2} \mathrm{H}_{5}, \mathrm{OCH}_{3}\right]$

$\mathrm{Z}:[\mathrm{H}, \mathrm{OH}, \mathrm{D}]$

$\mathrm{R}:\left[\mathrm{CCl}_{3}, \mathrm{CCl}_{2}, \mathrm{CHCl}_{2}, \mathrm{COOC}_{2} \mathrm{H}_{5}, \mathrm{CH}_{3}\right.$, $\left.\mathrm{CH}\left(\mathrm{NO}_{2}\right) \mathrm{C}_{2} \mathrm{H}_{5}, \mathrm{CH}\left(\mathrm{NO}_{2}\right) \mathrm{CH}_{3}\right]$

Figura 4: Estrutura Markush hipotética um defensivo agrícola. (KAUSHIK, 2007)

\footnotetext{
${ }^{18}$ É uma reivindicação com múltiplas entidades químicas "funcionalmente equivalentes" permitidas em um ou mais partes de um composto. O diagrama não descreve apenas uma estrutura, mas várias famílias de compostos. Tem um esqueleto base e substituintes que são listados como texto, separadamente do diagrama.
} 
Conforme Januzzi, Vasconcelos e Souza (2008), um grupo ou estrutura ou fórmula Markush é "uma expressão genérica para uma classe de substâncias químicas convencionalmente empregadas nas patentes, e consiste de um esqueleto molecular que é substituído por uma ou mais subestruturas variáveis que são acompanhadas da lista de definições destas porções variáveis da molécula".

Quantas moléculas estão contidas na estrutura Markush da figura 1? Para determinar o número de moléculas envolvidas, pode-se recorrer ao Princípio Fundamental da Contagem: se determinado acontecimento ocorre em $\mathrm{n}$ etapas diferentes, e se a primeira etapa pode ocorrer de k1 maneiras diferentes, a segunda de k2 maneiras diferentes, e assim sucessivamente, então o número total $\mathrm{T}$ de maneiras de ocorrer o acontecimento é dado por:

$T=k_{1} \times k_{2} \times k_{3} \times \ldots \times k_{n}$

Deste modo, há 4 × $3 \times 7$ ou 84 moléculas representadas na estrutura. Agora, as informações obtidas a partir da análise das exigências apontam para o banimento de organoclorados (moléculas com cloro em sua estrutura). Aplicando-se esta exigência, os radicais contendo cloro, na estrutura Markush, são eliminados. Recalculando-se o número de moléculas representadas com a imposição da restrição, verifica-se que há $3 \times 3 \times 4$ ou 36 moléculas, representando uma redução de $57,7 \%$ da condição inicial. Assim, se o exemplo fornecido refere-se a um processo industrial, a conclusão lógica é que com a redução da variabilidade de moléculas de partida, haverá redução do tempo e, dependo do caso, nos custos do desenvolvimento.

As limitações para esta metodologia referem-se à garantia da atividade biológica de cada molécula produzida, bem como na relação toxicidade versus estrutura molecular para os mais variados tipos de substâncias. No entanto, estas limitações não invalidam o método; devem servir como motivadoras de pesquisas de laboratório e de campo. Outra limitação é que esta metodologia deverá ser aplicada por pequenas e médias empresas localizadas em países em desenvolvimento, uma vez que é de se supor que as grandes empresas dos países desenvolvidos dispõem de metodologias mais avançadas. 
Nos últimos anos, a atividade empresarial foi profundamente alterada por eventos como a abertura de mercado, o desenvolvimento tecnológico e a globalização dos mercados. Além desses fatores, há pressões externas tais como novas regulamentações, novos padrões sanitários, padrões de certificação de qualidade e novas exigências dos mercados consumidores. Assim, atualmente as empresas precisam ser mais eficientes, mais rápidas e capazes de satisfazer a clientes cada vez mais exigentes. Neste cenário, a diferença entre "sobreviver" e "prosperar" pode estar em questões como o aprimoramento dos processos produtivos, de forma a permitir o acesso a mercados mais exigentes e a produção de artigos de melhor qualidade. Esta realidade é particularmente verdadeira para as empresas do setor de defensivos agrícolas.

\section{CONCLUSÕES}

O mundo das exigências ambientais é dinâmico. Os legisladores estão constantemente revisando as leis federais e os órgãos emitem rotineiramente novos regulamentos. Mais drasticamente, exigências regulatórias surgem de novos lugares na hierarquia legal, fazendo com que os requisitos ambientais tornem-se cada vez mais complicados e multifacetados. Deste modo, as empresas que não conseguirem monitorar os avanços da regulamentação, tanto em escala nacional quanto global, arriscam-se a ficar em séria desvantagem competitiva.

No mundo de hoje, nenhuma empresa, de pequeno ou grande porte, operando local ou globalmente, no setor industrial ou de serviços, pode se dar ao luxo de ignorar a vertente ambiental. Destarte, à medida que o mundo dos negócios acorda para o fato de que muitos recursos naturais são finitos, surge paralelamente uma segunda realidade: limites podem criar oportunidades.

A necessidade de abordar problemas ambientais difíceis pode ser a fagulha de que uma empresa necessita para sair da sua zona de conforto e encontrar maneiras de inovar. As metas de inovação impulsionam a criatividade, solicitando praticamente o impossível e demandando uma nova análise dos pressupostos vigentes. Forçam todos a buscar novas maneiras de suprir antigas necessidades. 
Exigências rígidas, em sua maior parte no nível federal, vêm orientando o progresso há décadas. Hoje, com o advento da globalização, a expansão do papel governamental, que passa a definir regras que vão desde comissões de planejamento local até acordos globais (criando novas demandas mundiais sobre as empresas), é um fenômeno que não pode ser desprezado. Novos regulamentos geram tanto vencedores quanto perdedores.

De fato, a inovação contínua na área de defensivos agrícolas (projetados para serem eficazes e ambientalmente amigáveis) se mostra vital para o sucesso das empresas de agroquímicos. No entanto, o aumento dos encargos regulatórios e a complexidade do produto têm impulsionado o aumento nos custos de pesquisa e desenvolvimento (P\&D).

Quem estiver mais bem posicionado para responder às novas regras será relativamente beneficiado pelas mudanças no campo de jogo. A empresa pode optar a continuar se queixando da legislação, cumprindo-a a duras penas, ou pode começar a enxergar as oportunidades de negócios para quem transcenda o mero cumprimento das leis. Na verdade, as empresas de ponta vão além do cumprimento básico de leis e normas; elas desenvolvem produtos inovadores para ajudar os clientes com problemas ambientais. Por meio de um processo de "gestão antecipatória de problemas", a empresa estuda as tendências ambientais e sociais, a fim de identificar as possíveis ameaças e oportunidades ao seu negócio.

Assim, ao invés da percepção negativa quanto aos requisitos ambientais, as empresas podem agir de forma positiva, não vendo os regulamentadores como inimigos a serem vencidos. Ao contrário, podem trabalhar com as autoridades governamentais para gerar incentivos e criar programas ambientais bem-sucedidos. Do ponto de vista estratégico, faz muito mais sentido associar-se aos regulamentadores e prever suas demandas (e expectativas públicas) do que desenvolver relacionamentos contenciosos.

O mundo empresarial está acordando para uma verdade inevitável: economia e meio ambiente estão profundamente interligados, onde a estratégia ambiental surge como ponto crítico de diferenciação competitiva. Com o esgotamento dos recursos 
naturais, base da economia é possível antever que, num futuro próximo, nenhuma empresa poderá alcançar a liderança do setor ou obter rentabilidade sustentada se não incorporar à sua estratégia as questões ambientais.

\section{REFERÊNCIAS}

ABIFINA. Associação Brasileira das Indústrias de Química Fina, Biotecnologia e Suas Especialidades. Site Institucional. Disponível em http://www.abifina.org.br/noticiaSecao.asp?secao=1\&noticia=1918. Arquivo consultado em 2013.

ANDEF. A Indústria de Defensivos Agrícolas: Inovação e Contribuições para o Agronegócio Brasileiro. Apresentação proferida por ocasião da VIII Reunião da Câmara Setorial de Oleaginosas e Biodiesel - MAPA. 11/05/2010 - Brasília-DF. Disponível

em: http://www.agricultura.gov.br/arg editor/file/camaras setoriais/Oleaginosas e biodies el/9 reuniao/ANDEF.pdf. Acesso em: 20 mar. 2013.

ANSANELLI, Stela Luiza de Mattos. Exigências ambientais externas como barreiras comerciais ao Brasil. Revista de Economia \& Relações Internacionais, vol.8(15), 2009.

BRASIL. Decreto № 4.074, de 4 de Janeiro De 2002. Regulamenta a Lei no 7.802, de 11 de julho de 1989, que dispõe sobre a pesquisa, a experimentação, a produção, a embalagem e rotulagem, o transporte, o armazenamento, a comercialização, a propaganda comercial, a utilização, a importação, a exportação, o destino final dos resíduos e embalagens, o registro, a classificação, o controle, a inspeção e a fiscalização de agrotóxicos, seus componentes e afins, e dá outras providências.

FERMAM, Ricardo K.S. Os Requisitos Ambientais no Comércio Internacional: Ferramentas de Acesso a Mercados para o Setor de Defensivos Agrícolas. 2009. 240 p. Tese (Doutorado em Ciências em Tecnologia de Processos Químicos e Bioquímicos). Escola de Química. Universidade Federal do Rio de Janeiro, Rio de Janeiro, 2009. 
FERMAM, Ricardo K.S.; ANTUNES, Adelaide. Requisitos ambientais e acesso a mercados: o setor de defensivos agrícolas. Rev. bras. polít. int., Brasília, v. 51, n. 2, Dec. $2008 . \quad$ Available from $<$ http://www.scielo.br/scielo.php?script=sci_arttext\&pid=S0034-

73292008000200003\&lng=en\&nrm=iso >. Acesso em: 25 mar. 2013. (http://dx.doi.org/10.1590/S0034-73292008000200003)

- Uso de Defensivos Agrícolas, Limites Máximos de Resíduos e Impacto no Comércio Internacional: Estudo de Caso. Revista de Economia e Agronegócio, VOL.7, № 2, 2009.

FLETCHER, S. R. High throughput approaches to designer products-myth or reality. Colloids and Surfaces A: Physicochemical and Engineering Aspects, Volume 288, Issues 1-3, 5 October 2006, Pages 21-25.

FLORES, Aracely Verônica et al. Organoclorados: um problema de saúde pública. Ambiente \& Sociedade - Vol. VII №. 2 jul./dez. 2004.

FRENKEL, Jacob e SILVEIRA, José Maria da. Tarifas, Preços e a Estrutura Industrial dos Insumos Agrícolas: O Caso dos Defensivos (Relatório Final). Texto Para Discussão no 412. Instituto de Pesquisa Econômica Aplicada (IPEA). Maio de 1996.

JANNUZZI, Anna Haydée Lanzillotti; VASCONCELLOS, Alexandre Guimarães; SOUZA, Cristina Gomes de. Especificidades do patenteamento no setor farmacêutico: modalidades e aspectos da proteção intelectual. Cad. Saúde Pública, Rio de Janeiro, v. 24, n. 6, June 2008. Available from $<$ http://www.scielo.br/scielo.php?script=sci_arttext\&pid=S0102-

311X2008000600002\&Ing=en\&nrm=iso>. Acesso em: 25 mar. 2013. (http://dx.doi.org/10.1590/S0102-311X2008000600002)

Kaushik, Poonam and Kaushik, Geetanjali. An assessment of structure and toxicity correlation in organochlorine pesticides. Journal of Hazardous Materials 143 (2007) 102-111. Elsevier. 
MMA. Ministério do Meio Ambiente. Convenção de Estocolmo. Disponível em http://www.mma.gov.br/seguranca-quimica/convencao-de-estocolmo. Acesso: 26 mar. 2013.

MAPA. Ministério da Agricultura, Pecuária e do Abastecimento. Site Institucional. Disponível na internet em http://www.agricultura.gov.br. Arquivo consultado em 2009.

MARTINELLI Jr, Orlando e WAQUIL, Paulo D. Tendências Recentes na Indústria de Defensivos Agrícolas no Brasil. Revista Análise Econômica, ano 19, n. 36, 2002. Faculdade de Ciências Econômicas. UFRGS.

NINAUT, Evandro Scheid e OLIVEIRA, Marco Olívio Morato de. Defensivos agrícolas: Seus efeitos na produtividade agrícola brasileira. Agroanalysis. v. 30(6), p.13-14. Junho/2010. Disponível

em: http://www.agroanalysis.com.br/materia detalhe.php?idMateria=853. Acesso: 28 mar. 2013.

OLIVEIRA E SILVA, M. F.de e DA COSTA, M. L. A indústria de defensivos agrícolas. BNDES Setorial 35, p. 233-276. Disponível em: http://www.bndes.gov.br/SiteBNDES/export/sites/default/bndes pt/Galerias/Arquivos/c onhecimento/bnset/set3507.pdf. Acesso: 20 mar. 2013.

Pesticide Development. Bayer Environmental Science (BES). Disponível na internet em http://www.bayer-escience.co.uk/pesticide development.htm. Arquivo consultado em 2007.

RIDLEY, S. M., ELLIOTT, A. C., YEUNG, M. and YOULE, D. (1998), High-throughput screening as a tool for agrochemical discovery: automated synthesis, compound input, assay design and process management. Pestic. Sci., 54: 327-337. doi: 10.1002/(SICI)1096-9063(199812)54:4<327::AID-PS828>3.0.CO;2-C.

Rotterdam Convention. Site Institucional. Disponível na internet em http://www.pic.int. Arquivo consultado em 2009. 
SCHNECKE, Volker and BOSTRÖM, Jonas. Computational chemistry-driven decision making in lead generation. Drug Discovery Today. Volume 11, Number 1/2. January 2006.

SILVEIRA, José Maria F.J. da e FUTINO, Ana Maria. O Plano Nacional de Defensivos Agrícolas e a Criação da Indústria Brasileira de Defensivos. Agricultura em São Paulo, SP, 37(3): 129-146, 1990.

STETTER J., 1998. Pesticide innovation: Trends in research and development. MFLBER, 63/2a, 135-181.

Stockholm Convention. Site Institucional. Disponível na internet em http://chm.pops.int. Arquivo consultado em 2009.

TASSEY, G. Underinvestment in Public Good Technologies. Journal of Technology Transfer, 30 1/2, 89-113, 2005.

Recebido: 15/08/2013

Aprovado: 28/11/2013 